\title{
VIRO-TypeNed, systematic molecular surveillance of enteroviruses in the Netherlands between 2010 and 2014
}

KSM Benschop 1, JC Rahamat-Langendoen 2 3, HGAM van der Avoort 1, ECJ Claas 4, SD Pas 5 , R Schuurman 6 , JJ Verweij 7 , KC Wolthers 8 , HGM Niesters 2 , MPG Koopmans 15 , on behalf of VIRO-TypeNed 9

1. Center for Infectious Disease Control, National Institute for Public Health and the Environment, Bilthoven, the Netherlands

2. Department of Medical Microbiology, University Medical Center Groningen, Groningen, the Netherlands

3. Current address: Department of Medical Microbiology, Radboud University Medical Center, Nijmegen, the Netherlands

4. Department of Medical Microbiology, Leiden University Medical Center, Leiden, the Netherlands

5. Department of Viroscience, Erasmus Medical Center, Rotterdam, the Netherlands

6. Department of Virology, University Medical Center Utrecht, Utrecht, the Netherlands

7. Laboratory of Medical Microbiology and Immunology, St Elisabeth Hospital, Tilburg, the Netherlands

8. Department of Medical Microbiology, Academic Medical Center, Amsterdam, the Netherlands

9. http://www.rivm.nl/Onderwerpen/T/Type_Ned/Type_Ned_Virologie

Correspondence: Kimberley S.M. Benschop (k.s.m.benschop@gmail.com)

Citation style for this article:

Benschop KSM, Rahamat-Langendoen JC, van der Avoort HGAM, Claas ECJ, Pas SD, Schuurman R, Verweij J, Wolthers KC, Niesters HGM, Koopmans MPG, on behalf of VIRO-TypeNed. VIRO-TypeNed, systematic molecular surveillance of enteroviruses in the Netherlands between 2010 and 2014 . Euro Surveill. 2016;21(39): pii=30352. DOI: http://dx.doi.org/10.2807/1560-7917.ES.2016.21.39.3035

Article submitted on 22 October 2015 / accepted on 23 May 2016 / published on 29 September 2016

VIRO-TypeNed is a collaborative molecular surveillance platform facilitated through a web-based database. Genetic data in combination with epidemiological, clinical and patient data are shared between clinical and public health laboratories, as part of the surveillance underpinning poliovirus eradication. We analysed the combination of data submitted from 2010 to 2014 to understand circulation patterns of non-polio enteroviruses (NPEV) of public health relevance. Two epidemiological patterns were observed based on VIRO-TypeNed data and classical surveillance data dating back to 1996: (i) endemic cyclic, characterised by predictable upsurges/outbreaks every two to four years, and (ii) epidemic, where rare virus types caused upsurges/outbreaks. Genetic analysis suggests continuous temporal displacement of virus lineages due to the accumulation of (silent) genetic changes. Non-synonymous changes in the antigenic B/C loop suggest antigenic diversification, which may affect population susceptibility. Infections were frequently detected at an age under three months and at an older, parenting age (25-49 years) pointing to a distinct role of immunity in the circulation patterns. Upsurges were detected in the summer and winter which can promote increased transmissibility underlying new (cyclic) upsurges and requires close monitoring. The combination of data provide a better understanding of NPEV circulation required to control and curtail upsurges and outbreaks.

\section{Introduction}

Enteroviruses (EVs) are widespread viruses circulating globally. More than 100 types, classified to the four species A to D within the genus Enterovirus of the
Picornaviridae family, are known to infect and cause disease in humans [1] The epidemiology of enteroviruses is characterised by the occurrence of seasonal peaks in the summer and temporal outbreaks that can be associated with life-threatening EV infections [2]. Clinical manifestations vary and range from asymptomatic or mild respiratory or gastrointestinal symptoms to severe and even fatal cases of myocarditis, neonatal sepsis, and central nervous system infections $[3,4]$. Severe and fatal cases often occur in children younger than five years or immunocompromised individuals [5-11]. Unfortunately, treatment options are limited and specific antivirals are not yet available $[12,13]$. Enteroviruses evolve by genetic diversification and recombination [14-17], which may affect their virulence [18-30]. In the Asian Pacific Region, EV-A71 (genotype $\mathrm{C}_{4}$ ) has been causing large outbreaks of hand, foot and mouth disease (HFMD) with severe complications since $2008[22,23]$. In a recent outbreak in the United States (US) and in Europe, an EV-D68 variant has been associated with outbreaks of severe respiratory disease and possibly paralysis [24-30]. While vaccination is a proven control strategy for some picornaviruses (poliovirus (PV), hepatitis A virus), little is known about the impact on population level of non-polio enteroviruses (NPEVs), even though these are among the most common endemic viruses. Knowledge on trends of NPEV illness comes from the decade-old EV surveillance programmes that have been implemented globally, where typing of enteroviruses from clinical samples from patients with polio-like illness is a cornerstone in the PV eradication campaign. Typing has historically been done by use of antigenic characterisation of virus isolates from routine diagnostic laboratories that used 
Distribution of endemic enterovirus types, the Netherlands, 1996-2014 (classical surveillance; $\mathrm{n}=4,098$ ) and 2010-2014 (VIRO-TypeNed; $\mathrm{n}=714$ )

A. $E-7$

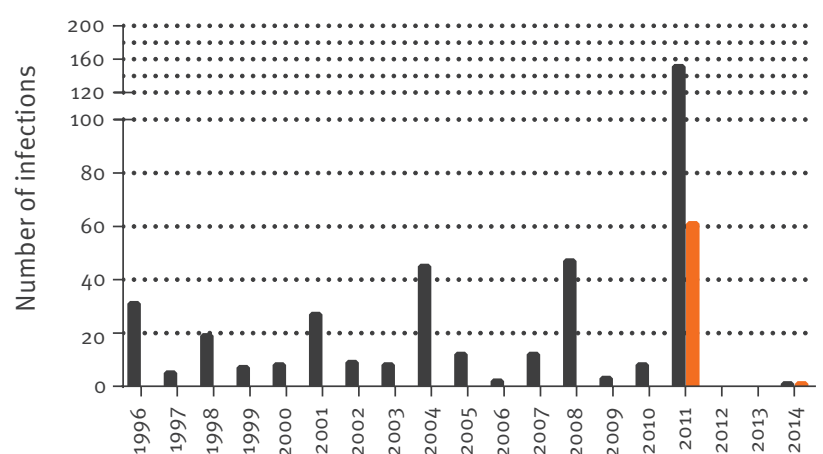

C. $E-18$

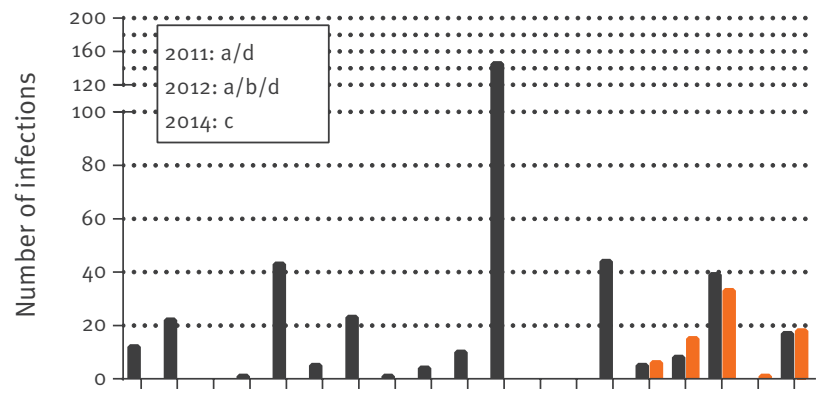

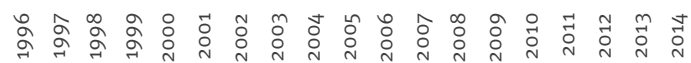

E. E-30

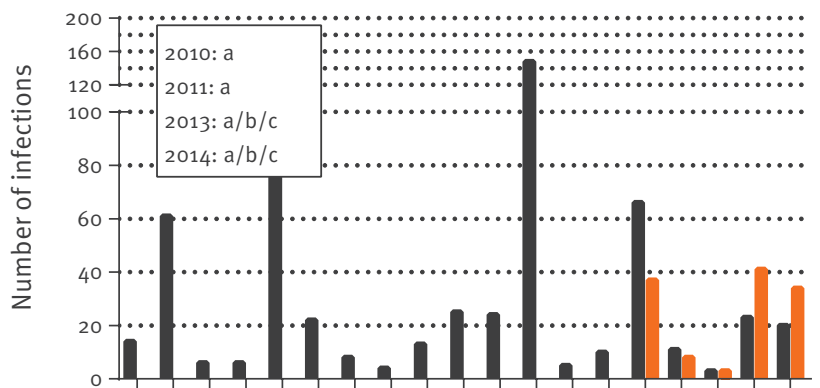

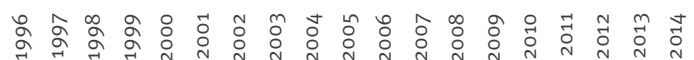

G. CV-B3

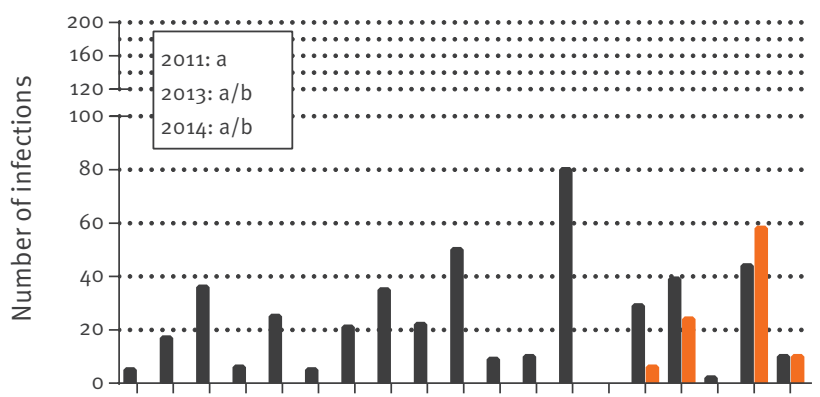

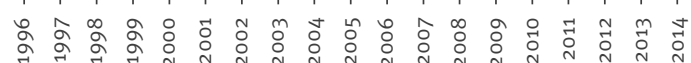

B. E-9

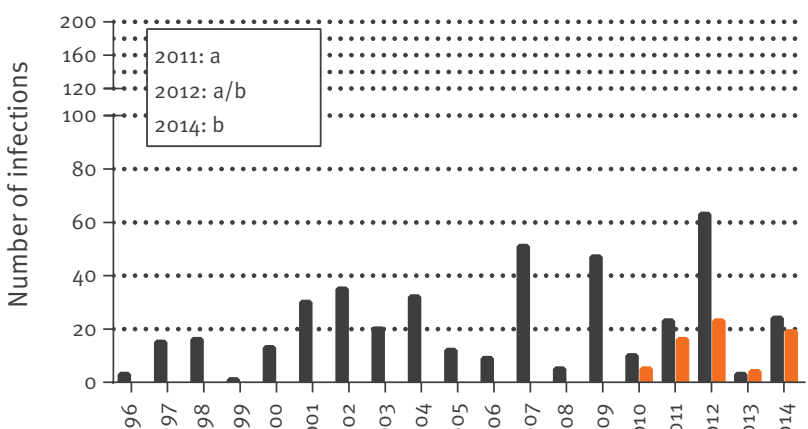

D. E-25

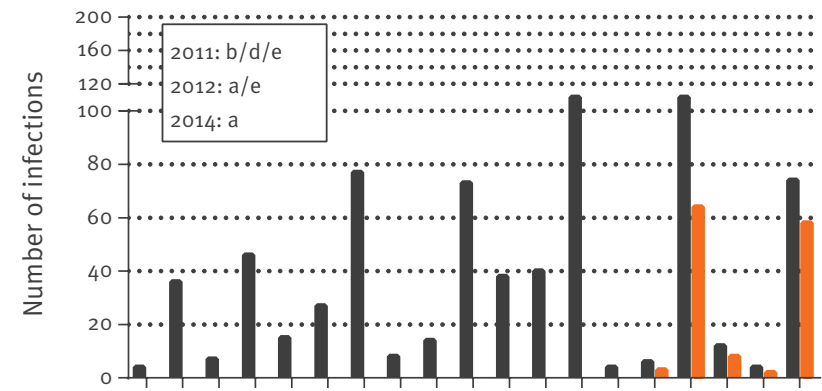

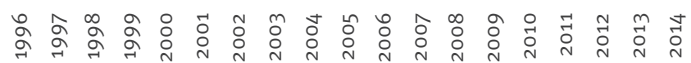

F. CV-A9

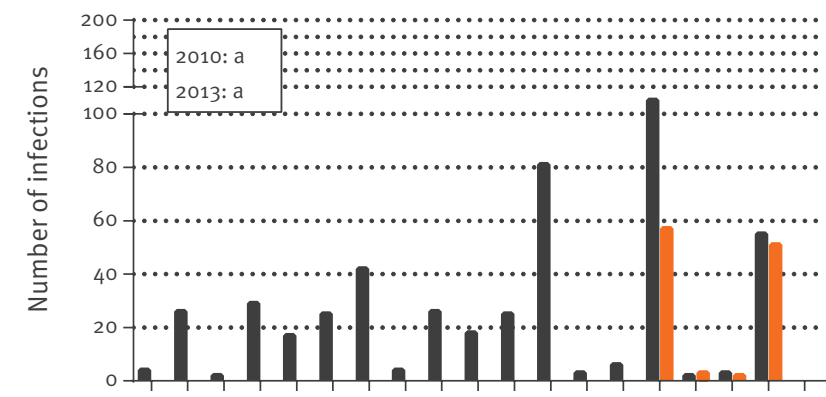

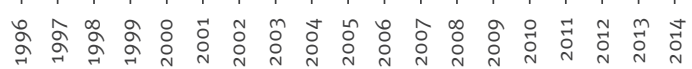

H. CV-B4

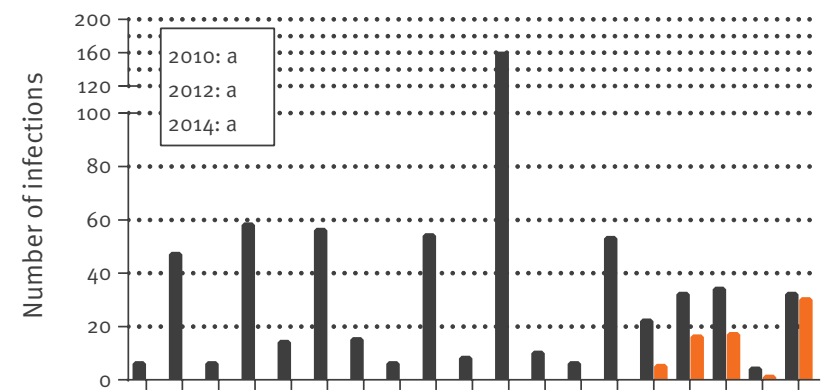

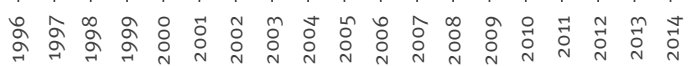

Classical surveillance VIRO-TypeNed 
cell culture as the primary diagnostic method. Now laboratories are switching more and more to molecular detection and typing methods [31,32]. A major drawback of the widespread introduction of fast molecular diagnostic methods is that the surveillance spin-off of NPEV from the EV surveillance programme is no longer routinely available, and that molecular typing is dedicated to a few larger diagnostic and university hospital centres. To compensate for this, we have launched a collaborative molecular surveillance programme in 2010, in which sequence-based surveillance was introduced (VIRO-TypeNed) [33].

Here, we present an analysis of data submitted through this novel surveillance system from 2010 through 2014, which provides a better understanding of NPEV circulation in relation to seasonal epidemics and outbreaks.

\section{Methods}

\section{Sampling and laboratory enterovirus diagnostic testing}

Stool, respiratory, cerebrospinal fluid (CSF), blood and vesicle fluid samples from patients of different age groups, admitted to or visiting the hospital with an EV-associated illness, were sent to the clinical virology laboratories for testing. Symptoms varied from mild to severe respiratory illness, fever and appearance of vesicles to central nervous symptoms such as meningitis. Enterovirus testing were done by enterovirus-specific PCR tests $[34,35]$, which are based on the conserved 5'UTR and enable detection of both PV and NPEVs, including those that do not grow in cell culture $[36,37]$.

\section{Virus characterisation of 5'UTR-positive samples}

Positive samples were characterised directly from clinical material or culture-positive samples by sequencing the $\mathrm{VP}_{1}$ gene $[31,38-40]$. The $\mathrm{VP}_{1}$ partial sequences obtained were used as input in the typing tool with an automated algorithm to assign the species and (sub) type of the sequences entered [41]. In addition, samples that could not be typed, in particular those with suspicion of PV infection, were sent to the reference laboratory (National Institute for Public Health and the Environment (RIVM)) for cultivation on the PV-specific cell line $L 20 B$ to document the absence of wild-type PV circulation. Laboratories that do not perform typing of EVs are encouraged to send EV isolates or 5'UTRpositive samples to the RIVM for exclusion of PV and further characterisation.

\section{Reporting of data for EV surveillance by VIRO-TypeNed}

The concept of VIRO-TypeNed has been described in detail elsewhere [33]. In short, participating Dutch clinical virology laboratories and the RIVM agreed on a consensus typing method described by Nix et al. [42] and on sharing of anonymised data in compliance with privacy rules via a secured web-based database. For each patient with a positive 5'UTR sample, at least one sequence of the VP1 gene generated by the Nix method is shared $[40,42]$. Sequences generated by other protocols can be included as well [43], but can only be included in the phylogenetic analysis when the region is compatible with the region generated with the Nix protocol. The VIRO-TypeNed platform includes a sequence-based typing tool with an automated algorithm to assign the species and (sub)type of the sequences entered, thus assuring comparability between the laboratories [41]. When available, a minimum set of clinical and epidemiological data are included with the submitted sequences, consisting of age, sex, date and type of sample, hospitalisation, travel history, clinical symptoms (skin, neurological, respiratory, enteric and other) and mortality.

\section{Data analysis}

We analysed data submitted during the first five years of the VIRO-TypeNed project for trends, clusters and genetic diversity of common enteroviruses. Using data from the classical enterovirus surveillance containing data dating back to 1996 [32], the circulation patterns of the types were defined as endemic cyclic or as epidemic: (i) types with an endemic cyclic pattern of circulation were characterised by (predictable) seasonal increases every two to four years, with low detection levels in intervening years and (ii) types with an epidemic pattern were characterised by a unique outbreak in a given year while being rare (detection level $n<10$ ) for at least 10 years before the given year [32].

To identify potential viral factors underlying the circulation patterns, all available partial $\mathrm{VP}_{1}$ gene sequences, which included the putative immunogenic B/C loop [44], were aligned and analysed for nucleotide and amino acid changes between lineages using the Simmonics sequence editor [45]. Pairwise distribution based on the nucleotide sequences of VP1 was calculated by MEGA6 [46] and used to set a demarcation cut-off to define lineages $[47,48]$. With the exception of EV-A71, classification of many NPEVs into lineages is not standardised. In cases where there is no uniform accepted lineage classification, lineages were designated alphabetically. EV-D68 lineages were designated as proposed by Tokarz et al. (A-C) [49] and Meijer et al. (I-III) [50].

\section{Results}

In the period from 2010 through 2014, six diagnostic and university hospital laboratories from different parts of the Netherlands participated in the network (University Medical Center Groningen, Leiden University Medical Center, Erasmus Medical Center Rotterdam, University Medical Center Utrecht, St Elisabeth Hospital Tilburg and Academic Medical Center Amsterdam). The RIVM reported genotyping results of samples referred by 17 of 26 virology laboratories across the Netherlands that do not perform typing. A total of 1,917 EV-positive samples that had been genotyped were reported during the study period. The EV-B species was the most frequently detected species in all five years taken 


\section{FIGURE 2}

Distribution of epidemic enterovirus types, the Netherlands, 1996-2014 (classical surveillance; n = 938 and 2010-2014 (VIRO-TypeNed; $\mathrm{n}=619$ )

\section{A. CV-A6}

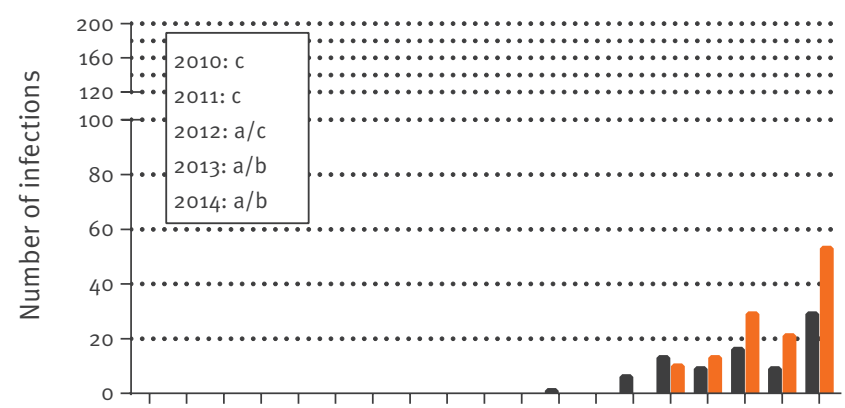

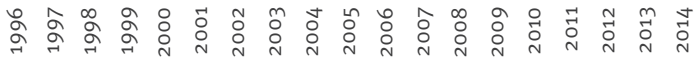

\section{EV-A71}

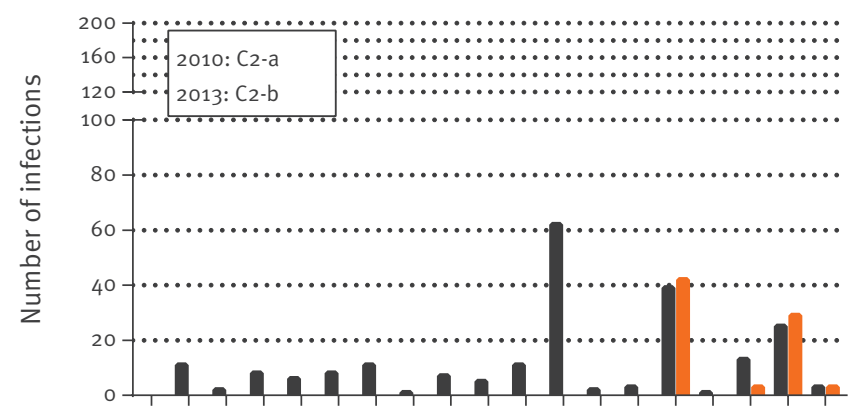

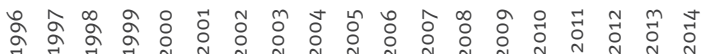

E. E-5

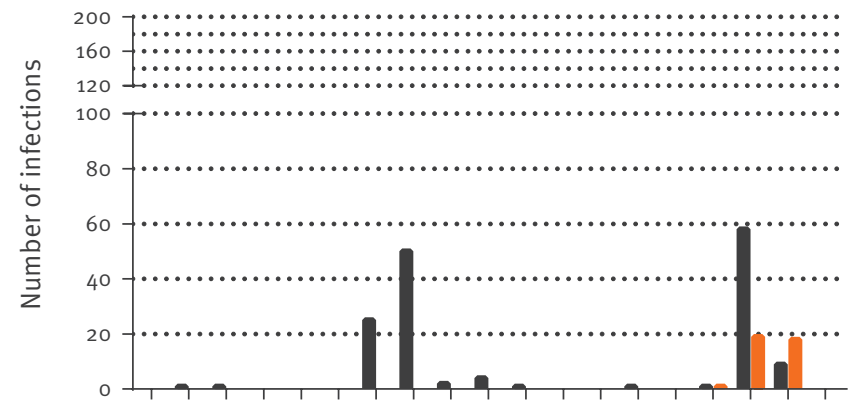

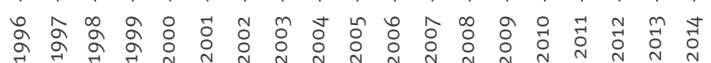

\section{B. CV-A16}

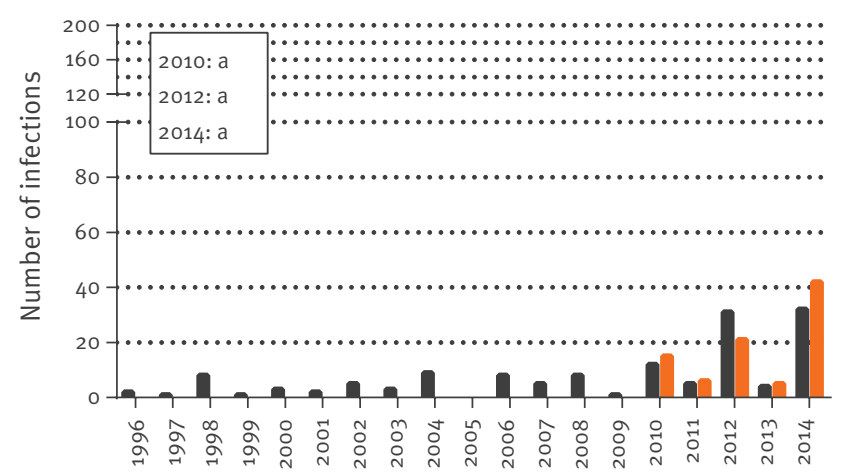

D. EV-D68

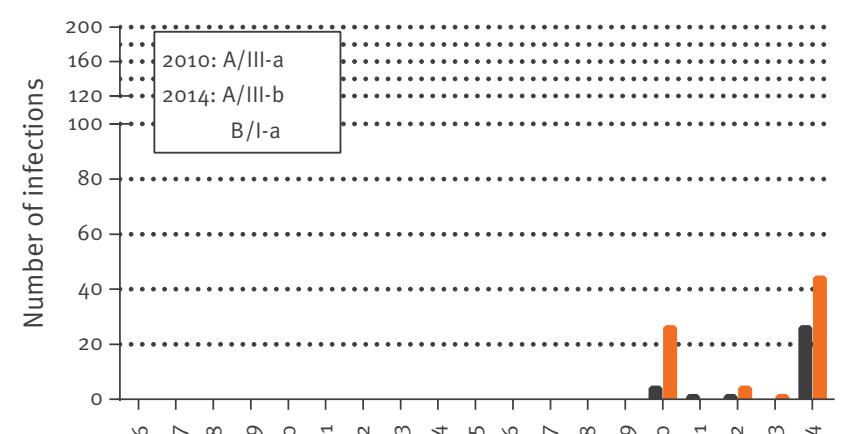

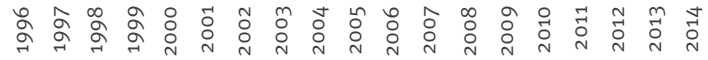

F. E-16

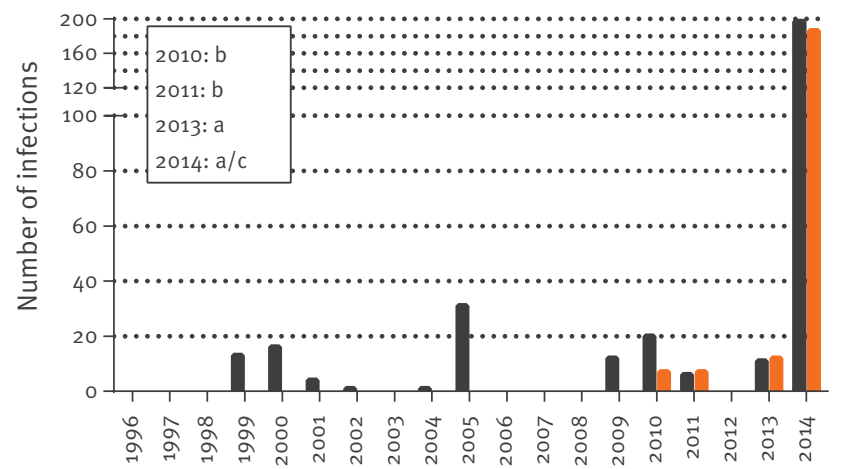

VIRO-TypeNed

Lineages are indicated in boxes in the graphs. Black bars indicate classical surveillance. Orange bars indicate VIRO-TypeNed data.

together, accounting for $70.3 \% \quad(n=1,347)$ of the viruses detected. The EV-A species comprised the second major species $(24.4 \%, n=467)$. The EV-C species and EV-D species (all identified as type EV-D68) accounted for $1.4 \%(n=25)$ and $4 \%(n=77)$, respectively, of the viruses detected. Oral PV vaccine (OPV) strains were detected in four patients; two cases in
2010 with OPV 2 and $\mathrm{OPV}_{3}$, respectively, and two cases in 2011 also with $\mathrm{OPV}_{2}$ and $\mathrm{OPV}_{3}$, respectively. The five most commonly reported types and their ranking varied each year and accounted in total for $49-63 \%$ of the infections identified (Table). 


\section{Endemic circulation}

Types that were characterised as endemic cyclic were E-25 $(n=136), E-30 \quad(n=123), C V-A 9 \quad(n=113), C V-B 3$ $(n=98), E-18(n=73), C V-B 4(n=69), E-9(n=67)$ and $\mathrm{E}-7(\mathrm{n}=62)$; they occurred with sharp peaks every two to four years (Figure 1). While there was no clear pattern indicative of evolution, phylogenetic clustering (data not shown) suggested the circulation of distinct genetic lineages that were defined by genetic changes in different motifs of the VP1 gene. E-9, E-18, E-25, E-30 and $\mathrm{CV}-\mathrm{B}_{3}$ lineages were temporally defined (Figure 1), indicating continuous temporal displacement of variants. CV-A9 and CV-B4 showed no sequence divergence between the years (Figure 1). All E-7 strains were collected in 2011 and were genetically similar. For all types, we found that the genetic changes were primarily silent. In addition to these silent changes, E-25, CV-B3 and E-9 variants showed amino acid substitutions within the $\mathrm{B} / \mathrm{C}$ loop, suggesting antigenic diversification over time. E-25 strains encoded a valine ( $V$, lineage $b$ and $d$ ) or threonine ( $T$, lineages $a$ and $e$ ) at position 78 and an aspartic acid ( $D$, lineage $b$ and $a$ ) or asparagine ( $\mathrm{N}$, lineage $\mathrm{d}$ and $\mathrm{e}$ ) at position 86 of the E-25 VP1 protein (amino acid numbering based on GenBank accession number HMo3119). CV-B3 strains encoded a lysine ( $\mathrm{K}$, lineage $\mathrm{a}$ ) or asparagine $(\mathrm{N}$, lineage b) at position 85 of the CV-B3-VP1 protein (numbering based on GenBank accession number JX312064) and $\mathrm{E}-9$ carried an asparagine $(\mathrm{N}$, lineage $\mathrm{a})$ or aspartic acid ( $D$, lineage b) at position 84 of the E-9 VP1 protein (numbering based on GenBank accession number AF524866) $[44,51,52]$.

\section{Epidemic circulation}

Types that were characterised as epidemic were $E-16$ $(n=212), \quad$ CV-A6 $(n=126), \quad$ CV-A16 $(n=89), \quad$ EV-A71 $(n=77$, of which 69 were C2), EV-D68 $(n=77)$ and E-5 $(n=38)$. E-16 was frequently reported in 2014 and was detected in $29 \%$ of the infections in the summer of 2014, which was twice as much than any other type detected in previous years (Figure 2).

Of interest is that CV-A6, CV-A16 and EV-A71 has continuously been detected in an endemic cyclic pattern since 2010 (Figure 2). Sequence divergence between CV-A6 lineages and EV-A71 C2 sublineages were primarily silent and were temporally defined (Figure 2), indicating the same continuous displacement of variants as seen for the endemic types. In contrast, CV-A16 variants did not display any significant sequence variations defining temporal clustering (Figure 2).

The shift from epidemic to endemic cycle was observed also for EV-D68. An upsurge of EV-D68 has been observed in 2010, after very low frequency for 14 years, and again in 2014 (Figure 2). The EV-D68 strains from 2010 and 2014 clustered as temporally defined sublineages within the previously assigned lineages A/III and $B / I$ (Figure 2). Sequence divergence between the two lineages showed amino acid substitutions within the $\mathrm{B} / \mathrm{C}$ loop; the variants of the $2014 \mathrm{~B} / \mathrm{I}$ lineage were found to encode D9o, T92 and alanine (A)95 of the VP1 protein (amino acid numbering based on GenBank accession ABo61487). The variants of the 2010 and $2014 \mathrm{~A} / \mathrm{III}$ lineages were found to encode N90, A92 (2010, lineage a) or T92 (2014, lineage b), and glutamic acid (E)95 (Figure 2).

\section{Patient characteristics}

Using additional patient data submitted to VIROTypeNed, we analysed factors such as age of infection, sex and clinical symptoms and their influence on the occurrence of endemic and epidemic patterns of the different types. The female:male sex ratio varied considerably between the types and there was no difference between endemic and epidemic types. Infections were frequently or equally found among girls for the endemic types CV-A9 (ratio: 0.9) and CV-B4 (ratio: 0.9), and the epidemic types EV-D68 (ratio: 0.7) and CV-A6 (ratio: 1). For most types, infections were frequently found among boys for the endemic types E-30 (ratio: 1.1), CV-B3 (ratio: 1.2), E-25 (ratio: 1.3), E-5 (ratio: 1.9), E-18 (ratio: 1.7), E-9 (ratio: 1.5), E-18 (ratio: 1.7) and E-7 (ratio: 2.4), and the epidemic types E-16 (ratio: 1.1), CV-A16 (ratio: 1.1) and EV-A71 (ratio: 1.5 ).

Overall, infections were detected in cases of all ages ( $<28$ days to 85 years) with a majority of cases younger than five years $(n=1,067 / 1,249 ; 56 \%)$. Cases infected with the epidemic types $\mathrm{E}-5$ and $\mathrm{E}-16$ were predominantly younger than three months ( $n=18 / 38 ; 47 \%$ and $n=159 / 212 ; 75 \%$, respectively). In contrast to the EV-B types characterised as either endemic or epidemic, cases infected with EV-A types were predominantly one to two years of age (25-35\%): CV-A6 ( $n=38 / 126)$, CV-A16 $(n=24 / 89), E V-A 71(n=19 / 77)$ and the EV-D type EV-D68 $(n=25 / 77)$. A number of viruses were also frequently found in adults (at parenting age, 25-45 years) in $3-20 \%$ of the cases: $E-30(n=15 / 123), C V-A 9$ $(n=11 / 113), E-18(n=8 / 73), C V-A 6(n=14 / 126), C V-A 16$ $(n=5 / 89)$ and EV-A71 $(n=3 / 77)$. Adult infections with EV-D68 were also frequently found among cases aged 45 to 65 years $(n=12 ; 16 \%)$. No adults with $E-25, C V-B 3$ and $\mathrm{E}-9$ infections were identified. Adults infected with other EV-B comprisedless than $1 \%$ of the infections. Clinical information was reported for only $5-30 \%$ of the cases. Nonetheless, it was found that all HFMD disease reports were attributed to EV-A infections (10/25, $p=0.003)$. Neurological symptoms were statistically more frequently reported among EV-B-infected cases $(85 / 129)$ compared with only a few EV-A-infected cases $(8 / 21)(p=0.027)$.

\section{Seasonal distribution}

Because typing data were linked to date of isolation, VIRO-TypeNed enabled direct analysis of seasonal trends of new upsurges of the common types as well as trends between the types. A clear seasonal distribution was observed in the years 2010, 2013 and 2014, with $15-29 \%$ of the EV infections observed in July and August of those years. In some years, there were clear seasonal peaks in winter, contrary to the summer peaks 
TABLE

The five most frequent non-polio enterovirus infections collected by VIRO-TypeNed, the Netherlands, 2010-2014 $(\mathrm{n}=1,917)$

\begin{tabular}{|l|c|c|c|c|c|}
\hline Ranking & 2010 & 2011 & 2012 & 2013 & 2014 \\
\hline 1 & CV-A9 & E-25 & E-18 & CV-B3 & E-16 \\
\hline 2 & EV-A71 & E-7 & CV-A6 & CV-A9 & E-25 \\
\hline 3 & E-30 & CV-B3 & E-9 & E-30 & CV-A6 \\
\hline 4 & EV-D68 & CV-B4 & CV-A16 & EV-A71 & CV-A16 \\
\hline 5 & CV-A16 & E-9 & E-5 & CV-A6 & EV-D68 \\
\hline
\end{tabular}

The ranking is based on the number of cases recorded.

that are considered typical for enteroviruses. In 2011 and 2012, most EV infections detected in those years were found in the late fall and winter 2011/12 (October to February; detection ranged from $16 \%$ in October 2011 to $9 \%$ in February 2012). In contrast, not many summer infections were reported in those years $(11 \%$ in July 2011 and 6\% in August 2012). When an upsurge was detected aftermore than 10 years of low EV activity, the epidemic types CV-A6, CV-A16, EV-D68 and E-5 were predominantly detected in the winter. For CV-A6, CV-A16 and EV-D68, the seasonality shifted towards summer and fall in the following years.

\section{Discussion}

In this paper, we describe the systematic surveillance of NPEVs for the Netherlands through the VIROTypeNed system, which is based on molecular typing of pathogens.

By analysing virus sequence data in combination with epidemiological and patient data, we show for the first time in a standardised manner the circulation patterns of NPEVs in the Netherlands enabling a better understanding of NPEV circulation, which is required to control and curtail outbreaks and upsurges. With the knowledge on the endemic cyclic patterns, a rise in the number of positive cases two to four years after the last upsurge warrants vigilance because it could indicate an imminent upsurge/outbreak [53]. Of interest is the shift from an epidemic to an endemic pattern for CV-A6, CV-A16, EV-A71 and EV-D68; this should be taken into account when monitoring rare types. For the EV-A viruses, the observed shift could be a surveillance artefact due to the change in detection methods from culture to molecular, as molecular methods have increased sensitivity and capture viruses that are more difficult to culture, such as these EV-A viruses [3133,36]. Another explanation could be a change in pathogenicity. We found a low level of circulation of EV-D68 (before 2010) and EV-C viruses, which is consistent with other studies (reviewed by [31]) and is suggested to be related to a low pathogenicity of these types [43]. Indeed, in 2010 and 2014, hospitals in Europe and the US reported increased detection of EV-D68 in respiratory samples from cases with severe respiratory disease [24-29,50,54-57].
The increase was related to genetic changes that could have driven a more severe pathogenicity rather than to changes in detection methods [50]. Unfortunately, clinical data were missing in the majority of cases of other viruses and more data are required to investigate whether pathogen drift could have additionally contributed to the increased detection of other NPEVS in certain years.

The data further suggest that the epidemic/endemic cyclic patterns might be driven by immunity; this could be due to antigenic diversification, waning immunity or simply lack of immunity. The frequency of infections at an extremely young age and at parenting age [58-60] suggests lack of protection by maternal antibodies [61]. Lack of immunity or waning immunity can be inversely related to the endemic cyclic patterns of the different types/strains; the types/strains that adults are exposed to are different from those circulating during their childhood when they frequently came in contact with EVs. An adult's immunity profile is thus directed against EV types not currently circulating, which has led to a high proportion of susceptible adults. In the case of antigenic diversification, the immunity that was predominantly built up in previous years may be lacking (loss of neutralisation capacity) or not effective against currently circulating antigenic variants (altered neutralisation capacity) [62]; this also leads to a high proportion of susceptible adults $[24,50,54]$. For EV-D68, the high proportion of infection among adult cases aged 45 to 65 years, and the divergence between the two lineages showing amino acid substitutions within the $B / C$ loop, indeed suggest that antigenic diversification leading to altered neutralisation capacity plays a role in adult infections $[50,54]$. In contrast, E-30, CV-A9, E-18, CV-A6, CV-A16 and EV-A71, all frequently observed in adult infections, showed no antigenic diversification. However, we cannot rule out the occurrence of antigenic diversification among these types, as antigenic epitopes can also be found among other exposed VP1 loops and on other capsid proteins $[44,51,52]$ not characterised by the Nix protocol.

Furthermore, no adults were identified among E-25, CV-B3 and E-9, strains proposed to have antigenic diversification. This would suggest that other factors act as a transmission bottleneck, such as differential receptor expression between adults and children. It has been suggested that viral characteristics such as receptor usage can account for the differential age of infection with several EV types and $\operatorname{HPeV}[19,63]$.

Another factor affecting the circulation patterns is seasonality. It has been suggested that infection frequency is dependent on the number of contacts or transmissions, which can be influenced by the season or the weather. The frequency of contacts is highest during the winter months [64-66], which could spur widespread transmission after an initial introduction and lead to unexplained illness outbreaks during winter season. The observed winter peak could be 
related to the introduction of fast molecular methods that allowed rapid screening of samples throughout the years, revealing a more diverse seasonal pattern. EV should therefore also be considered in the differential diagnosis during winter seasons, contrary to the dogma describing EV infections as seasonal summer infections.

To investigate and understand the role of these factors (antigenic diversification, lack of or waning immunity, and seasonality) on the circulation pattern, full-length genetic and phenotypic analysis in combination with sero-population studies need to be conducted over an extended period. VIRO-TypeNed provides a platform to analyse these data in relation to one another.

Knowledge about the endemic/epidemic patterns can be used to investigate the possibility of type-specific vaccines [67]. Meanwhile, the data can be used to prescreen intravenous immunoglobulin (IVIG) products, where the knowledge of which types are currently circulating can enable a more effective use of IVIGs.

Furthermore, with the current developments in the antiviral field, EV infections may soon be classified as treatable rather than life-threatening [13]. The drugs currently in development show type-specific efficacy $[68,69]$ and use requires the knowledge of which types are currently circulating or may cause an outbreak.

While VIRO-TypeNed provides data on NPEVs, the system also allows reporting the detection of PV. PV circulation might occur through inadvertent introduction of OPV, vaccine-derived PV (VDPV) or even wild-type $\mathrm{PV}$, or via faecal excretions from migrants or travellers returning from endemic or OPV-using countries. Any type of PV isolation in the Netherlands leads to a public health alert because there is a large unvaccinated group ( $3 \%$ of the population) refusing vaccination for religious reasons that live in a closely isolated community (the Bible Belt). The 5'UTR PCR is able to detect all EVs including PV. Over the period studied, four OPV strains were reported. They had been detected by direct genotyping from clinical samples and had already been notified to the RIVM, and preventive actions for further spread had been taken. Given the very low circulation rate of PV in the Netherlands in non-epidemic years, EV-positive samples from which unique NPEV sequences are generated are considered PV-negative. However, as positive untyped samples can contain PV, laboratories are encouraged to send these samples, in particular those with suspicion of PV infection, to the RIVM for cultivation on L2OB cells. As such, the surveillance capacity to exclude PV circulation in a molecular era is maintained.

\section{Acknowledgements}

We want to thank all the virologists participating in the Weekly Sentinel Surveillance System of the Dutch Working Group for Clinical Virology for collecting and providing positive samples for PV exclusion and NPEV typing. We would also like to thank Erwin Duizer for critically reading the manuscript and the laboratory staff of Laboratories participating in the VIRO-TypeNed project: Edin Jusic, and Jeroen Cremer (RIVM); Jolanda Kreeft-Voermans en Mark Verbeek (Erasmus MC); Lisette Rusman (LUMC); Hèlen van Raak en Judith Beuving (St Elisabeth Hospital); Gerrit Koen, Hetty van Eijk, Xiomara Thomas, Rene Minnaar, Karen DijkamndeHaan, Sjoerd Rebers (AMC); Randy Poelman, Coretta Van Leer-Buter, Renze Borger (UMCG).

Katja wolthers is partially funded by the Seventh Framework Programme of the European Union IAPP under contract PIAPP-GA-2013-612308 (AIROPico, www, airopico.eu).

Conflict of interest

None declared.

Authors' contributions

Kimberley Benschop performed the analyses of the data and wrote the first draft of the paper. Kimberley Benschop, Janette Rahamat-Langendoen Harrie van der Avoort, Eric. Claas, Suzan Pas, Rob Schuurman, Jaco Verweij, Katja Wolthers, and Hubert Niesters were responsible for collecting and recording the data in VIRO-TypeNed. Marion Koopmans critically reviewed the draft of the paper. All other authors reviewed the paper critically, and comments and suggestions were incorporated in the final version by Kimberley Benschop.

\section{References}

1. The picornavirus pages. Enterovirus. Pirbright; The Pirbright Institute. [Accessed: 14 Sep 2016]. Available from: http://www. picornaviridae.com/enterovirus/enterovirus.htm

2. Abzug MJ. Presentation, diagnosis, and management of enterovirus infections in neonates.Paediatr Drugs. 2004;6(1):110. DOI: $10.2165 / 00148581-200406010-00001$ PMID: 14969566

3. Grist NR, Bell EJ, Assaad F. Enteroviruses in human disease. Prog Med Virol. 1978;24:114-57.PMID: 360295

4. Mohle-Boetani JC, Matkin C, Pallansch M, Helfand R, Fenstersheib $M$, Blanding JA, et al. Viral meningitis in child care center staff and parents: an outbreak of echovirus 30 infections. Public Health Rep. 1999;114(3):249-56. DOI: 10.1093/phr/114.3.249 PMID: 10476994

5. Hawkes MT, Vaudry W. Nonpolio enterovirus infection in the neonate and young infant.Paediatr Child Health. 2005;10(7):383-8.PMID: 19668644

6. Fuchs I, Golan A, Borer A, Shemer-Avni Y, Dagan R, Greenberg D. Proactive approach to containment of enterovirus infection in the nursery.Clin Pediatr (Phila). 2013;52(7):639-44. DOI: 10.1177/0009922813484087 PMID: 23572447

7. Verma NA, Zheng XT, Harris MU, Cadichon SB, MelinAldana $\mathrm{H}$, Khetsuriani $\mathrm{N}$, et al. Outbreak of life-threatening coxsackievirus B1 myocarditis in neonates. Clin Infect Dis. 2009;49(5):759-63. DOI: 10.1086/605089 PMID: 19622042

8. Modlin JF. Fatal echovirus 11 disease in premature neonates. Pediatrics. 1980;66(5):775-80.PMID: 7432883

9. Gear JH, Measroch V. Coxsackievirus infections of the newborn. Prog Med Virol. 1973;15:42-62.PMID: 4572439

10. Freund MW, Kleinveld G, Krediet TG, van Loon AM, VerboonMaciolek MA. Prognosis for neonates with enterovirus myocarditis.Arch Dis Child Fetal Neonatal Ed. 2010;95(3):F20612. DOI: 10.1136/adc.2009.165183 PMID: 20444813

11. Kaplan MH, Klein SW, McPhee J, Harper RG. Group B coxsackievirus infections in infants younger than three months of age: a serious childhood illness. Rev Infect Dis. 1983;5(6):1019-32. DOI: 10.1093/clinids/5.6.1019 PMID: 6318288

12. Wildenbeest JG, van den Broek PJ, Benschop KS, Koen G, Wierenga PC, Vossen AC, et al. Pleconaril revisited: clinical course of chronic enteroviral meningoencephalitis after treatment correlates with in vitro susceptibility. Antivir Ther. 2012;17(3):459-66. DOI: 10.3851/IMP1936 PMID: 22293148 
13. Benschop KS, van der Avoort HG, Duizer E, Koopmans MP. Antivirals against enteroviruses: a critical review from a public-health perspective. Antivir Ther. 2015;20(2):121-30. DOI: 10.3851/IMP2939 PMID: 25643052

14. Simmonds $P$, Welch J. Frequency and dynamics of recombination within different species of human enteroviruses.J Virol. 2006;80(1):483-93. DOI: 10.1128/ JVI.80.1.483-493.2006 PMID: 16352572

15. Lukashev AN, Lashkevich VA, Ivanova OE, Koroleva GA, Hinkkanen AE, Ilonen J. Recombination in circulating enteroviruses.J Virol. 2003;77(19):10423-31. DOI: 10.1128/ JVI.77.19.10423-10431.2003 PMID: 12970427

16. Lukashev AN. Role of recombination in evolution of enteroviruses.Rev Med Virol. 2005;15(3):157-67. DOI: 10.1002/ rmv.457 PMID: 15578739

17. McWilliam Leitch EC, Cabrerizo M, Cardosa J, Harvala $\mathrm{H}$, Ivanova OE, Kroes AC, et al. Evolutionary dynamics and temporal/geographical correlates of recombination in the human enterovirus echovirus types 9,11 , and 30 . J Virol. 2010;84(18):9292-300. DOI: 10.1128/JVI.00783-10 PMID: 20610722

18. Savolainen C, Hovi T, Mulders MN. Molecular epidemiology of echovirus 30 in Europe: succession of dominant sublineages within a single major genotype.Arch Virol. 2001;146(3):521-37. DOI: $10.1007 /$ s007050170160 PMID: 11338388

19. Harvala H, Kalimo H, Bergelson J, Stanway G, Hyypiä T. Tissue tropism of recombinant coxsackieviruses in an adult mouse model.J Gen Virol. 2005;86(Pt 7):1897-907. DOI: 10.1099/ vir.0.80603-o PMID: 15958668

20. Harvala H, Kalimo H, Dahllund L, Santti J, Hughes P, Hyypiä $\mathrm{T}$, et al. Mapping of tissue tropism determinants in coxsackievirus genomes. J Gen Virol. 2002;83(Pt 7):1697-706. DOI: 10.1099/0022-1317-83-7-1697 PMID: 12075089

21. Harvala H, Kalimo H, Stanway G, Hyypiä T. Pathogenesis of coxsackievirus $\mathrm{A} 9$ in mice: role of the viral arginine-glycine aspartic acid motif.J Gen Virol. 2003;84(Pt 9):2375-9. DOI: 10.1099/vir.0.19246-0 PMID: 12917458

22. Ooi MH, Wong SC, Lewthwaite P, Cardosa MJ, Solomon T. Clinical features, diagnosis, and management of enterovirus 71.Lancet Neurol. 2010;9(11):1097-105. DOI: 10.1016/S14744422(10)70209-X PMID: 20965438

23. Sun LM, Zheng HY, Zheng HZ, Guo X, He JF, Guan DW, et al. An enterovirus 71 epidemic in Guangdong Province of China, 2008: epidemiological, clinical, and virogenic manifestations. Jpn J Infect Dis. 2011;64(1):13-8.PMID: 21266750

24. Meijer A, Benschop KS, Donker GA, van der Avoort HG. Continued seasonal circulation of enterovirus D68 in the Netherlands, 2011-2014.Euro Surveill. 2014;19(42):20935. DOI: 10.2807/1560-7917.ES2014.19.42.20935 PMID: 25358039

25. Esposito S, Zampiero A, Ruggiero L, Madini B, Niesters H, Principi N. Enterovirus D68-associated community-acquired pneumonia in children living in Milan, Italy.J Clin Virol. 2015;68:94-6. DOI: 10.1016/j.jcv.2015.05.017 PMID: 26071345

26. Farrell JJ, Ikladios O, Wylie KM, O’Rourke LM, Lowery KS, Cromwell JS, et al. Enterovirus D68-associated acute respiratory distress syndrome in adult, United States, 2014. Emerg Infect Dis. 2015;21(5):914-6. DOI: 10.3201/ eid2105.142033 PMID: 25897542

27. Lang M, Mirand A, Savy N, Henquell C, Maridet S, Perignon R, et al. Acute flaccid paralysis following enterovirus D68 associated pneumonia, France, 2014. Euro Surveill. 2014;19(44):20952. DOI: 10.2807/1560-7917. ES2014.19.44.20952 PMID: 25394254

28. Midgley SE, Christiansen CB, Poulsen MW, Hansen $\mathrm{CH}$, Fischer TK. Emergence of enterovirus D68 in Denmark, June 2014 to February 2015. Euro Surveill. 2015;20(17):21105. DOI: 10.2807/1560-7917.ES2015.20.17.21105 PMID: 25955773

29. Pfeiffer HC, Bragstad K, Skram MK, Dahl H, Knudsen PK, Chawla MS, et al. Two cases of acute severe flaccid myelitis associated with enterovirus D68 infection in children, Norway, autumn 2014. Euro Surveill. 2015;20(10):21062. DOI: 10.2807/1560-7917.ES2015.20.10.21062 PMID: 25788251

30. Poelman R, Schuffenecker I, Van Leer-Buter C, Josset L, Niesters HG, Lina B, et al. European surveillance fo enterovirus D68 during the emerging North-American outbreak in 2014. J Clin Virol. 2015;71:1-9. DOI: 10.1016/j.jcv.2015.07.296 PMID: 26364237

31. Janes VA, Minnaar R, Koen G, van Eijk H, Dijkman-de Haan $K$, Pajkrt D, et al. Presence of human non-polio enterovirus and parechovirus genotypes in an Amsterdam hospital in 2007 to 2011 compared to national and international published surveillance data: a comprehensive review. Euro Surveill. 2014;19(46):20964. DOI: 10.2807/1560-7917. ES2014.19.46.20964 PMID: 25425513
32. van der Sanden SM, Koopmans MP, van der Avoort HG. Detection of human enteroviruses and parechoviruses as part of the national enterovirus surveillance in the Netherlands, 1996-2011. Eur J Clin Microbiol Infect Dis. 2013;32(12):1525-31. DOI: 10.1007/S10096-013-1906-9 PMID: 23780695

33. Niesters HG, Rossen JW, van der Avoort H, Baas D, Benschop $\mathrm{K}$, Claas EC, et al. Laboratory-based surveillance in the molecular era: the TYPENED model, a joint data-sharing platform for clinical and public health laboratories. Euro Surveill. 2013;18(4):20387.PMID: 23369392

34. Benschop K, Molenkamp R, van der Ham A, Wolthers K, Beld M. Rapid detection of human parechoviruses in clinical samples by real-time PCR.J Clin Virol. 2008;41(2):69-74. DOI: 10.1016/j. jcv.2007.10.004 PMID: 18354819

35. Poelman R, Schölvinck EH, Borger R, Niesters HG, van Leer-Buter C. The emergence of enterovirus D68 in a Dutch University Medical Center and the necessity for routinely screening for respiratory viruses.J Clin Virol. 2015;62:1-5. DOI: 10.1016/j.jcv.2014.11.011 PMID: 25542461

36. Benschop K, Minnaar R, Koen G, van Eijk H, Dijkman K, Westerhuis $B$, et al. Detection of human enterovirus and human parechovirus (HPeV) genotypes from clinical stool samples: polymerase chain reaction and direct molecular typing, culture characteristics, and serotyping. Diagn Microbiol Infect Dis. 2010;68(2):166-73. DOI: 10.1016/j. diagmicrobio.2010.05.016 PMID: 20846590

37. Beld M, Minnaar R, Weel J, Sol C, Damen M, van der Avoort $\mathrm{H}$, et al. Highly sensitive assay for detection of enterovirus in clinical specimens by reverse transcriptionPCR with an armored RNA internal control. J Clin Microbiol. 2004;42(7):3059-64. DOI: 10.1128/JCM.42.7.3059-3064.2004 PMID: 15243060

38. Benschop K, Thomas X, Serpenti C, Molenkamp R, Wolthers K. High prevalence of human Parechovirus (HPeV) genotypes in the Amsterdam region and identification of specific $\mathrm{HPeV}$ variants by direct genotyping of stool samples.J Clin Microbiol. 2008;46(12):3965-70. DOI: 10.1128/JCM.01379-08 PMID: 18945833

39. Oberste MS, Maher K, Flemister MR, Marchetti G, Kilpatrick DR, Pallansch MA. Comparison of classic and molecular approaches for the identification of untypeable enteroviruses.J Clin Microbiol. 2000;38(3):1170-4.PMID: 10699015

40. Oberste MS, Maher K, Kilpatrick DR, Flemister MR, Brown $B A$, Pallansch MA. Typing of human enteroviruses by partial sequencing of VP1.J Clin Microbiol. 1999;37(5):1288-93.PMID: 10203472

41. Kroneman A, Vennema H, Deforche K, van der Avoort H, Peñaranda S, Oberste MS, et al. An automated genotyping tool for enteroviruses and noroviruses. J Clin Virol. 2011;51(2):121-5. DOI: 10.1016/j.jcv.2011.03.006 PMID: 21514213

42. Nix WA, Oberste MS, Pallansch MA. Sensitive, seminested PCR amplification of VP1 sequences for direct identification of all enterovirus serotypes from original clinical specimens.J Clin Microbiol. 2006;44(8):2698-704. DOI: 10.1128/JCM.00542-06 PMID: 16891480

43. Harvala H, McLeish N, Kondracka J, McIntyre CL, McWilliam Leitch EC, Templeton K, et al. Comparison of human parechovirus and enterovirus detection frequencies in cerebrospinal fluid samples collected over a 5-year period in edinburgh: HPeV type 3 identified as the most common picornavirus type. J Med Virol. 2011;83(5):889-96. DOI: 10.1002/jmv.22023 PMID: 21412796

44. Page GS, Mosser AG, Hogle JM, Filman DJ, Rueckert RR, Chow $M$. Three-dimensional structure of poliovirus serotype 1 neutralizing determinants.J Virol. 1988;62(5):1781-94.PMID: 2451757

45. Simmonds P. SSE: a nucleotide and amino acid sequence analysis platform.BMC Res Notes. 2012;5(1):50. DOI: 10.1186/1756-0500-5-50 PMID: 22264264

46. Kumar S, Tamura K, Nei M. MEGA3: Integrated software for Molecular Evolutionary Genetics Analysis and sequence alignment.Brief Bioinform. 2004;5(2):150-63. DOI: 10.1093/ bib/5.2.150 PMID: 15260895

47. Benschop KS, Williams CH, Wolthers KC, Stanway G, Simmonds P. Widespread recombination within human parechoviruses: analysis of temporal dynamics and constraints.J Gen Virol. 2008;89(Pt 4):1030-5. DOI: 10.1099/vir.0.83498-0 PMID: 18343846

48. McWilliam Leitch EC, Bendig J, Cabrerizo M, Cardosa J, Hyypiä T, Ivanova OE, et al. Transmission networks and population turnover of echovirus 30. J Virol. 2009;83(5):2109-18. DOI: 10.1128/JVI.02109-08 PMID: 19091869

49. Tokarz R, Firth C, Madhi SA, Howie SR, Wu W, Sall AA, et al. Worldwide emergence of multiple clades of enterovirus 68. J 
Gen Virol. 2012;93(Pt 9):1952-8. DOI: 10.1099/vir.0.043935-0 PMID: 22694903

50. Meijer A, van der Sanden S, Snijders BE, Jaramillo-Gutierrez G, Bont L, van der Ent CK, et al. Emergence and epidemic occurrence of enterovirus 68 respiratory infections in The Netherlands in 2010. Virology. 2012;423(1):49-57. DOI: 10.1016/j.virol.2011.11.021 PMID: 22177700

51. Cordey S, Petty TJ, Schibler M, Martinez Y, Gerlach D, van Belle $\mathrm{S}$, et al. Identification of site-specific adaptations conferring increased neural cell tropism during human enterovirus 71 infection. PLoS Pathog. 2012;8(7):e1002826. DOI: 10.1371/ journal.ppat.1002826 PMID: 22910880

52. Baek K, Yeo S, Lee B, Park K, Song J, Yu J, et al. Epidemics of enterovirus infection in Chungnam Korea, 2008 and 2009. Virol J. 2011;8(1):297. DOI: 10.1186/1743-422X-8-297 PMID: 21668960

53. Savolainen-Kopra C, Paananen A, Blomqvist S, Klemola P, Simonen ML, Lappalainen $M$, et al. A large Finnish echovirus 30 outbreak was preceded by silent circulation of the same genotype. Virus Genes. 2011;42(1):28-36. DOI: 10.1007/s11262010-0536-x PMID: 20960045

54. Rahamat-Langendoen J, Riezebos-Brilman A, Borger R, van der Heide R, Brandenburg A, Schölvinck E, et al. Upsurge of human enterovirus 68 infections in patients with severe respiratory tract infections. J Clin Virol. 2011;52(2):103-6. DOI: 10.1016/j.jcv.2011.06.019 PMID: 21802981

55. Ayscue P, Van Haren K, Sheriff H, Waubant E, Waldron P, Yagi S, et al. Acute flaccid paralysis with anterior myelitis California, June 2012-June 2014. MMWR Morb Mortal Wkly Rep. 2014;63(40):903-6.PMID: 25299608

56. Khan F. Enterovirus D68: acute respiratory illness and the 2014 outbreak.Emerg Med Clin North Am. 2015;33(2):e19-32. DOI: 10.1016/j.emc.2014.12.011 PMID: 26065305

57. Midgley CM, Jackson MA, Selvarangan R, Turabelidze G, Obringer E, Johnson D, et al. Severe respiratory illness associated with enterovirus D68 - Missouri and Illinois, 2014. MMWR Morb Mortal Wkly Rep. 2014;63(36):798-9.PMID: 25211545

58. Nougairede A, Bessaud M, Thiberville SD, Piorkowski G, Ninove $\mathrm{L}$, Zandotti C, et al. Widespread circulation of a new echovirus 30 variant causing aseptic meningitis and non-specific viral illness, South-East France, 2013. J Clin Virol. 2014;61(1):118-24. DOI: 10.1016/j.jcv.2014.05.022 PMID: 24973284

59. Milia MG, Cerutti F, Gregori G, Burdino E, Allice T, Ruggiero $T$, et al. Recent outbreak of aseptic meningitis in Italy due to Echovirus 30 and phylogenetic relationship with other European circulating strains. J Clin Virol. 2013;58(3):579-83. DOI: $10.1016 / j . j c v .2013 .08 .023$ PMID: 24051044

6o. Ramirez-Fort MK, Downing C, Doan HQ, Benoist F, Oberste MS, Khan F, et al. Coxsackievirus A6 associated hand, foot and mouth disease in adults: clinical presentation and review of the literature. J Clin Virol. 2014;60(4):381-6. DOI: 10.1016/j. jcv.2014.04.023 PMID: 24932735

61. Rabenau HF, Richter M, Doerr HW. Hand, foot and mouth disease: seroprevalence of Coxsackie A16 and Enterovirus 71 in Germany. Med Microbiol Immunol (Berl). 2010;199(1):45-51. DOI: $10.1007 /$ s00430-009-0133-6 PMID: 19941005

62. McPhee F, Zell R, Reimann BY, Hofschneider PH, Kandolf R. Characterization of the $\mathrm{N}$-terminal part of the neutralizing antigenic site I of coxsackievirus $\mathrm{B}_{4}$ by mutation analysis of antigen chimeras.Virus Res. 1994;34(2):139-51. DOI: 10.1016/0168-1702(94)90096-5 PMID: 7531922

63. Westerhuis BM, Koen G, Wildenbeest JG, Pajkrt D, de Jong MD, Benschop KS, et al. Specific cell tropism and neutralization of human parechovirus types 1 and 3 : implications for pathogenesis and therapy development. J Gen Virol. 2012;93(Pt 11):2363-70. DOI: 10.1099/vir.0.043323-0 PMID: 22837420

64. Yarmolskaya MS, Shumilina EY, Ivanova OE, Drexler JF, Lukashev AN. Molecular epidemiology of echoviruses 11 and 30 in Russia: different properties of genotypes within an enterovirus serotype.Infect Genet Evol. 2015;30:244-8. DOI: 10.1016/j.meegid.2014.12.033 PMID: 25562123

65. Moeller JL. Aseptic meningitis: a seasonal concern.Phys Sportsmed. 1997;25(7):34-42. DOI: $10.3810 / p s m .1997 .07 .1472$ PMID: 20086919

66. David JM, Ravel A, Nesbitt A, Pintar K, Pollari F. Assessing multiple foodborne, waterborne and environmental exposures of healthy people to potential enteric pathogen sources: effect of age, gender, season, and recall period.Epidemiol Infect. 2014;142(1):28-39.PMID: 23731678

67. Pallansch MA, Oberste MS. Enterovirus 71 encephalitis: a new vaccine on the horizon?Lancet. 2013;381(9871):976-7. DOI: 10.1016/S0140-6736(13)60286-X PMID: 23668563

68. Oberste MS, Moore D, Anderson B, Pallansch MA, Pevear DC, Collett MS. In vitro antiviral activity of V-073 against
polioviruses.Antimicrob Agents Chemother. 2009;53(10):45013. DOI: 10.1128/AAC.00671-09 PMID: 19635956

69. Thibaut HJ, De Palma AM, Neyts J. Combating enterovirus replication: state-of-the-art on antiviral research.Biochem Pharmacol. 2012;83(2):185-92. DOI: 10.1016/j.bcp.2011.08.016 PMID: 21889497

\section{License and copyright}

This is an open-access article distributed under the terms of the Creative Commons Attribution (CC BY 4.0) Licence. You may share and adapt the material, but must give appropriate credit to the source, provide a link to the licence, and indicate if changes were made.

This article is copyright of the authors, 2016. 